This PDF is a selection from a published volume from the National Bureau of Economic Research

Volume Title: Health Care Issues in the United States and Japan

Volume Author/Editor: David A. Wise and Naohiro Yashiro, editors

Volume Publisher: University of Chicago Press

Volume ISBN: 0-262-90292-7

Volume URL: http://www.nber.org/books/wise06-1

Conference Date: May 1-3, 2003

Publication Date: September 2006

Title: An International Look at the Medical Care Financing Problem

Author: David M. Cutler

URL: http://www.nber.org/chapters/c7360 


\title{
An International Look at the Medical Care Financing Problem
}

\author{
David M. Cutler
}

Virtually all developed countries are worried about how to finance medical care. Medical costs are increasing more rapidly than tax revenues to pay for them, and populations are aging, each of which increases the burden on the public sector. In the United States, we speak of a Medicare crisis and a Social Security crisis, where the government will no longer be able to meet its health care bills. Other countries have an aging crisis, or an old age insurance crisis.

There is no doubt that medical care costs are certain to increase. But by how much? What is the magnitude of reform that is needed? Those are the questions I address in this paper.

To answer them, I develop a forecast model of medical spending in Organization for Economic Cooperation and Development (OECD) countries. The model uses as inputs current spending on medical care and the demographic mix of the population as it stands now and as it is expected to change. The model estimates the share of medical spending in gross domestic product (GDP) in the future. Because most countries pay for the bulk of medical services publicly, this forecast is closely related to the increase in the public-sector financing burden that can be expected.

The results yield several important conclusions. First, all OECD countries can expect an increase in the cost of medical care over time. On the basis of demographic change alone, the typical country can expect medical

David M. Cutler is the Otto Eckstein Professor of Applied Economics, Department of Economics and John F. Kennedy School of Government, and social sciences dean in the Faculty of Arts and Sciences, both at Harvard University, and a research associate of the National Bureau of Economic Research.

I am grateful to the National Institutes on Aging for research support, and to Seiritsu Ogura for comments on a previous draft. 
care to increase by 2.2 percent of GDP in the next thirty years and by 3.6 percent of GDP in the next half century. Including continued technological innovation in medicine at the rate experienced in the past raises the projected increase in the next thirty years to 5.7 percent of GDP. Interestingly, the data suggest that the medical care problem is about equally split between the consequences of aging and the consequences of technological change in medical treatments.

The coming medical care burden differs substantially across countries. The countries that will be hardest hit by demographic change are Spain, Switzerland, the Czech Republic, Italy, and Greece. All of these countries have very low fertility rates and large projected increases in life expectancy. Demographic change will raise medical spending in these countries by 5 to 6 percent of GDP. Japan and the United States rank in the middle on this scale, ninth and twelfth, respectively, out of twenty-nine countries (expected increases of 4.4 and 3.7 percent). The least affected countries include Turkey, the United Kingdom, New Zealand, and Mexico, with an expected increase of 2 percent or less.

Accounting for technological change has a material impact on these rankings. Most importantly, it raises the financing burden in the United States. The United States spends more than other countries do on medical care and has the most technologically advanced medical system. Thus, if technology increases costs at the same rate everywhere, the United States will be particularly hard hit. Using historical growth rates of medical costs as a guide to the future, the projected increase in medical spending in the United States over the next thirty years is close to 10 percent. The increase in Japan will be over 6 percent of GDP.

These are sizeable estimates, although perhaps not cataclysmic. I show that affording such increases will require reductions in the growth of nonmedical consumption, but not absolute declines in the level of such spending.

This paper is structured as follows. Section 3.1 lays out the nature of the medical care problem and the structure of the simulation model. Section 3.2 describes the consequences of demographic change alone. Section 3.3 then adds in technological change in medical treatments. Section 3.4 discusses the implications for the affordability of medical care overall, and section 3.5 concludes.

\subsection{Forecasting Medical Care Spending}

The need to forecast medical spending is obvious. Medical care is 10 percent of GDP or more in most developed countries and is growing rapidly. Most of this medical care is paid for by the public sector (over 80 percent in most countries). Thus, public concern about rising costs is particularly high. But medical costs are a concern in the private sector as well. In- 
creased medical spending involves painful adjustments as families shift their spending allocations among different goods and businesses pass on the costs of medical care to workers. None of this implies that medical spending increases are bad, but it indicates why we need to know what the medical burden will be.

Forecasting medical spending is simple in some ways and horribly complex in others. To understand the issues, I start with a truism: medical spending as a share of GDP is the division of per capita medical spending by per capita output. To forecast the share of GDP devoted to medical care, therefore, I forecast these two terms.

Start with medical spending. Per capita medical spending is the product of the number of people at each age times spending at that age, divided by the number of people in the country as a whole. Denoting age groups with the subscript $a$, this can be expressed as

$$
\text { Per capita medical spending }=\sum_{a} \text { Pop }_{a} \cdot \frac{\text { Spend }_{a}}{\text { Total Pop }} .
$$

To forecast medical spending, therefore, we need projections of the population and spending at each age.

The United Nations publishes projections of population by age (United Nations Population Division 1998). The United Nations divides the population into people below age fifteen, people aged fifteen to sixty-four, and people over the age of sixty-five. I use these population projections at decadal intervals through 2050.

Forecasting spending in each age group is more difficult. Relative medical spending by age differs across countries, and the growth of overall spending differs across countries. Aging is more of a problem in countries where medical spending is more highly tilted to the aged and in countries where overall cost growth is more rapid. It is not clear what assumptions about spending growth are reasonable. For these simulations, I make relatively simple assumptions, based on data availability as much as economic theory.

The first assumption is about relative medical spending at each age. There is not a lot of data on relative medical spending by age in different countries, as the microdata that are needed for this analysis are not always available. For simplicity, I assume that the age distribution of medical spending is the same in all countries and is equal to the distribution in the United States. In the United States, the elderly spend 3 times what the adult population does on medical care, and the young spend 60 percent less than the adult population. As populations age, therefore, there will be a monotonic increase in spending.

Almost certainly, the elderly share in the United States is higher than in most other countries, as the technological intensity of the U.S. system is particularly brought to bear at older ages. If other countries keep spending 
for the elderly down in the future, this would blunt the impact of aging in those countries. Conversely, if spending on the elderly rises in other countries, to match the technological intensity of the United States, most other countries could face an even greater spending burden than my forecasts suggest.

I further assume that relative spending will remain the same at different ages in the future. In the United States, spending on the aged has increased more rapidly than spending on the nonaged, as technological change has tilted toward the elderly (Cutler and Meara 1998, 2001). In the absence of better information, however, there is little ability to forecast continued changes in this ratio.

The second assumption is about the impact of medical technology on costs. As the capabilities of medicine expand, what will happen to overall medical spending? It is clear that increases in the technical sophistication of medicine have been a fundamental factor in rising medical costs in the past, far surpassing the roles of increased income, more generous insurance, and an older population on medical costs (Newhouse 1992; Technical Review Panel on the Medicare Trustees' Reports 2000). The reason is clear-medical technology moved diseases from untreatable to treatable. For example, coronary bypass surgery replaced watchful waiting as a primary therapy for people with a heart attack in the 1980s and 1990s. Monitoring without intervention is cheap; bypass surgery is expensive. Hence, developing bypass surgery led to increased medical spending.

There is no indication that technological change is becoming less rapid. If anything, it is speeding up with the genomic revolution and advances in traditional therapies such as surgeries and diagnostic equipment (JAMA 2001). Thus, one might expect that medical spending will continue to increase.

But the translation between technological change and spending is more complex. Where lack of treatment was once the norm, today most conditions are treated in some fashion. As a result, in the future, new treatments will increasingly substitute for older ones. If the newer procedures are cheaper than the older procedures they replace, the use of new procedures may not lead to as rapid cost increase. To follow the heart attack example, angioplasty recently joined bypass surgery as a recognized therapy for heart attacks. Some angioplasties substitute for bypass surgery. Because angioplasty is cheaper than bypass surgery, the use of this technology saves money in some cases (Cutler and Huckman 2003). ${ }^{t}$

The ultimate impact of technological change on medical spending depends on the relative importance of these treatment expansion and treatment substitution effects. It will not necessarily be the case that medical

1. In total, though, angioplasty led to more spending, as it substituted for medical management in many people. 
spending continues to rise as medicine becomes more technologically sophisticated.

Most forecasts suggest that technological change will increase to increase spending, however. A consensus estimate is that medical spending will increase 1 percent more rapidly than GDP in the next few decades (Medicare Technical Advisory Panel 2000). I use this estimate in my simulations.

Translating this estimate internationally requires additional assumptions. Medical spending is lower in other countries than in the United States. If medical costs increase 1 percent more rapidly than GDP everywhere, the dollar increase will be smaller abroad than in the United States. Thus, there will be a growing divergence between medical costs in different countries. Is this possible? In principle, yes. Even though medical technology has expanded in all countries over the past half century, the increase has been far larger in the United States than elsewhere, as figure 3.1 shows. The United States has thus become even more of an outlier than it was already. For lack of a better alternative, I assume this will continue in the future. One issue for future exploration is the implications of assuming some convergence in spending.

In addition to forecasting medical spending, we need to forecast per capita income. We can express per capita income using a formula similar to equation (1):

$$
\text { Per capita income }=\sum_{a} \text { Workers }_{a} \cdot \frac{\text { Output }_{a}}{\text { Total Pop }}
$$

A complete projection of equation (2) would forecast the number of workers at each age along with output of those workers. No projections that detailed are available. I thus make simpler assumptions. I assume that

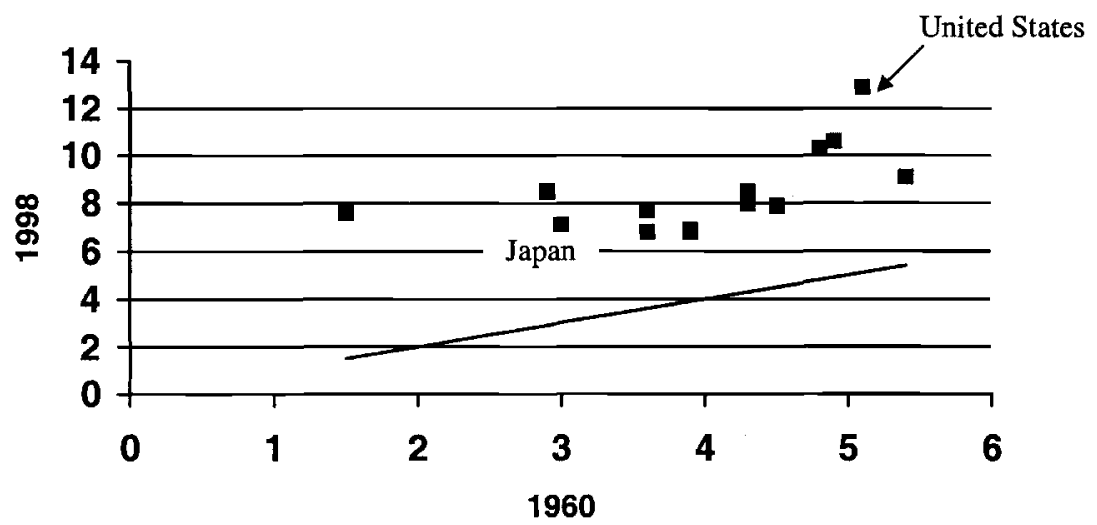

Fig. 3.1 Medical spending as a share of GDP Source: OECD (2002). 
labor force participation is confined to the fifteen- to sixty-four-year-old population and that labor force participation in that group remains constant. Further, I assume that output for all workers rises at the same rate. For these simulations, the rate of increase is immaterial; the key is the differential between health care cost growth and output growth. As discussed previously, I assume this differential is 1 percent.

Effectively, these assumptions mean that changes in output are driven entirely by changes in share of the population that is working age. As a first-pass simulation model, this does not seem unreasonable.

\subsection{Demographics and Medical Spending}

To understand the medical care problem, I start with some basic demographic information across countries. The share of the population that is elderly varies greatly across the developed world. Figure 3.2 shows this variation. Thirteen percent of the OECD as a whole is over the age of sixtyfive. Italy has the largest elderly share, at 18 percent, with Greece, Sweden, Japan, and Spain also being very high. For all of the worries about aging in the United States, the United States population is not very elderly (by developed country standards); 12 percent of the U.S. population is over age sixty-five.

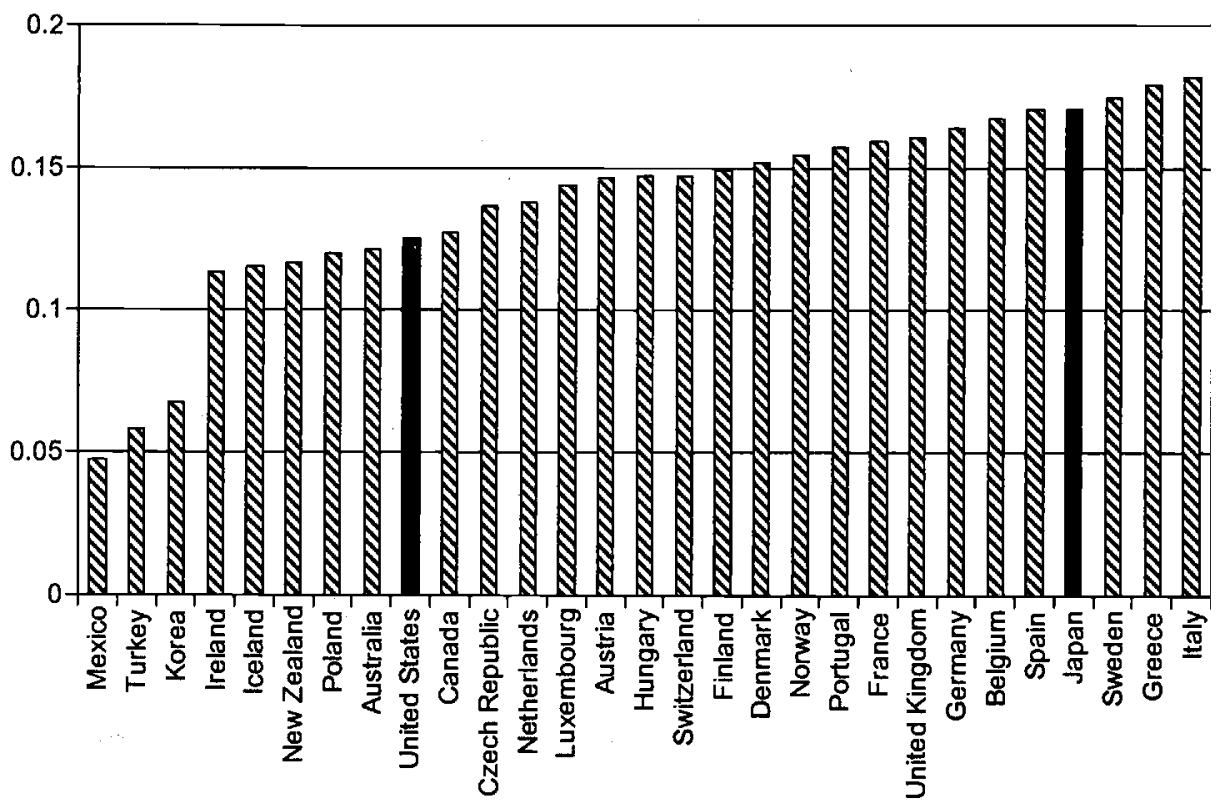

Fig. 3.2 Elderly share of the population, 2000 Source: United Nations Population Division (1998). 
The major driver of aging is fertility. Most countries have fertility rates that are below replacement levels (about 2.1 births per woman). Italy, for example, has a birth rate of 1.2 babies per woman, and Japan is 1.4. Birth rates this low inevitably imply an aging population. Added to the low fertility rate are increases in longevity at older ages. In the United States, the average forty-five-year-old lives nearly five years longer now than in 1950 . Finally, immigration rates are low in most OECD countries. Immigration from poor to rich countries does not change the world's share of elderly people, but it does change the share in any particular country. A country with low net immigration will be increasingly older.

The net impact of these demographic changes is a projection of substantial increases in the elderly population over time. Figure 3.3 shows the forecast increase in the elderly share between 2000 and 2050 . The expected increase is large in all countries. The highest rates of increase are forecast in Spain, the Czech Republic, Korea, and Italy. These countries will see increases in the elderly population of over 15 percentage points if nothing else intervenes. The average OECD country will experience an increase of 11 percentage points, and even countries at the very low end (the United

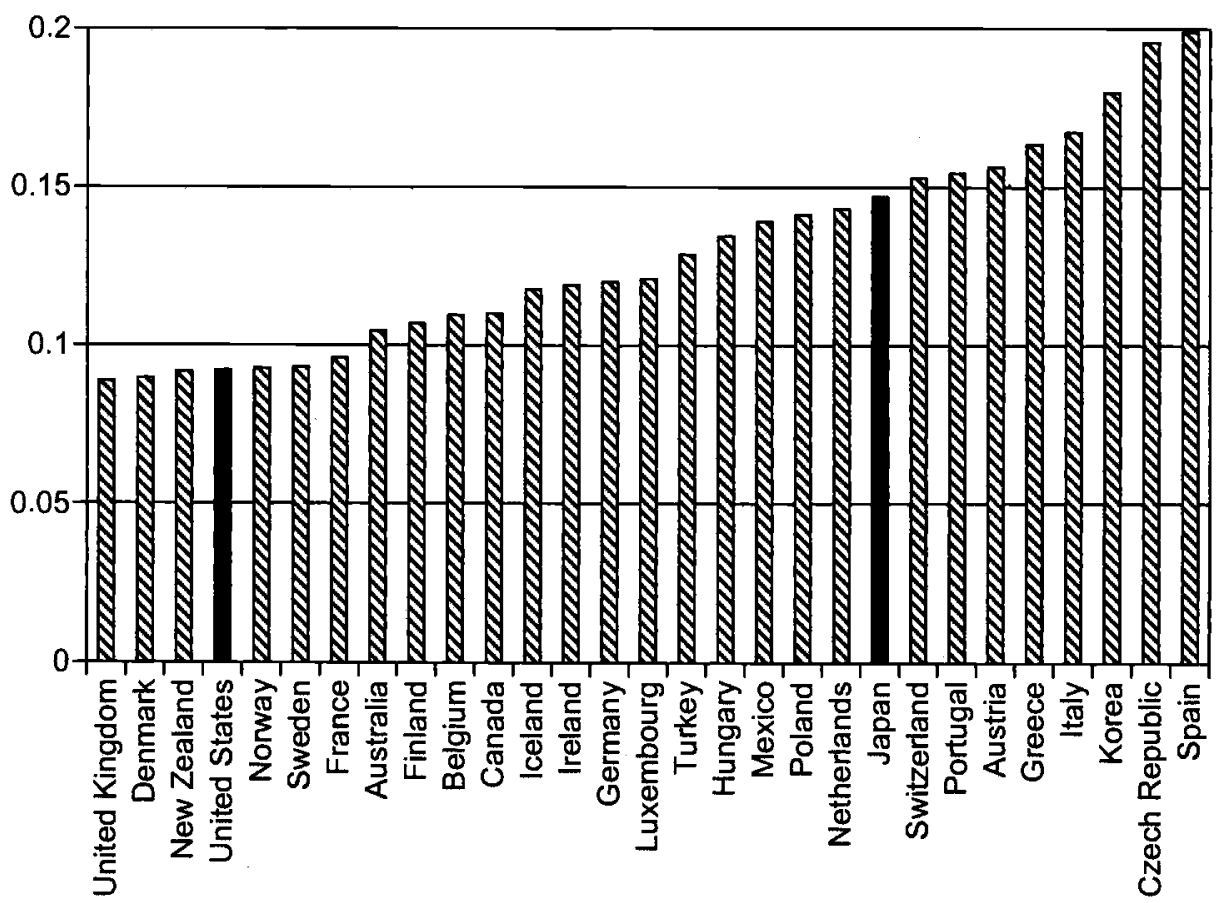

Fig. 3.3 Forecast change in elderly share of the population, 2000-2050

Source: United Nations Population Division (1998). 
Kingdom and the United States, for example) will have increases of 9 percentage points.

One sunny side of aging is fewer children, and thus more workers among the nonelderly population (Cutler et al. 1990). This is not enough to overwhelm the effect of increased elderly shares on medical spending, however. To examine the effect of demographic changes on the medical system, I simulate spending assuming no change in per person medical care utilization in the next half century. While this is obviously unrealistic, it provides a benchmark to assess the importance of demographic changes.

The results of the simulation are shown in figure 3.4. Note the mean first. In the average OECD country, demographic change alone will increase medical spending as a share of GDP by 3.6 percentage points in the next half century. This is a large increase, but perhaps not insurmountable. Most of this increase is in the next thirty years, where the increase will average 2.2 percentage points. The retirement of the baby boom generation will lead the procession into an era of more rapidly rising medical costs.

The ranking of countries is similar in figure 3.4 as in figure 3.3 , but the two are not exactly the same. The countries with the biggest increase are

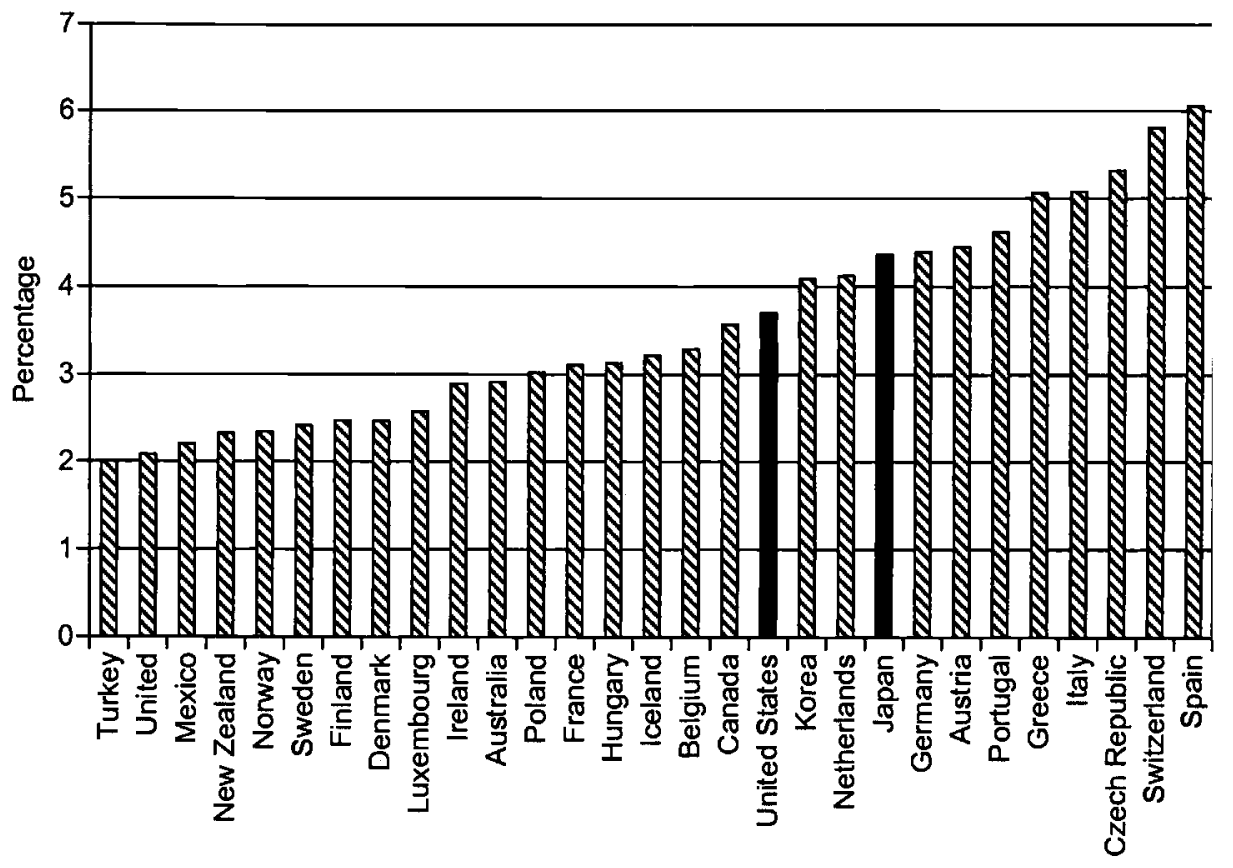

Fig. 3.4 Forecast change in medical care share of GDP, demographic change only, 2000-2050

Source: Author's calculations. 
Spain, Switzerland, the Czech Republic, Italy, and Greece. All of these countries will have medical spending increases of over 5 percent of GDP, based on demographic change alone. The United States is higher ranked in figure 3.4 than in figure 3.3. Because medical spending in the United States is so high, the same amount of demographic change has a larger impact on per capita spending than it does elsewhere. The forecast increase in the United States is 3.7 percentage points. In Japan, the forecast increase is 4.4 percentage points.

At the bottom of the list are Turkey and the United Kingdom. The comparatively low rate of aging in the United Kingdom combined with a low level of medical spending blunts the impact of demographic change on medical costs. But even in the United Kingdom, demographic change will lead to a 2 percent increase in the share of medical care in GDP. It is clear that demographic change will present a financing hurdle for all developed countries.

\subsection{Including Technological Change}

A more complete simulation includes the effects of technological change as well as population aging. As noted previously, I assume that medical costs increase at all ages by 1 percent per year above the rate of per capita GDP growth. Forecast out forever, this is clearly unrealistic; it implies that medical care would ultimately account for all of GDP. Thus, some limit on the time period for forecasting is needed.

To illustrate the importance of technical change, I consider a more limited simulation of medical spending in the next thirty years, to 2030. A steady increase in costs over the next three decades is (perhaps) more realistic than assuming the same increase over the next fifty years.

Figure 3.5 shows the resulting estimates of the change in medical spending relative to GDP. Even in the next thirty years, the simulation implies large increases in medical spending. In the average OECD country, the increase in GDP share is 5.7 percentage points. That is greater than the 2.2 percentage points attributable to demographic change in this time period, although the additional part due to technical change (3.5 percentage points) is not much larger than the demographic component.

Most notable in figure 3.5 are the enormously high increases projected in Switzerland and the United States. Medical spending in each of those countries is projected to increase by over 9 percent, to levels of about 25 percent of GDP. The medical cost problem is more severe in these countries because medical spending in those countries is so high. Hence, continued increases in costs result in disproportionately large increases in the medical sector. In Japan, the increase in the medical care burden is between 6 and 7 percent. 


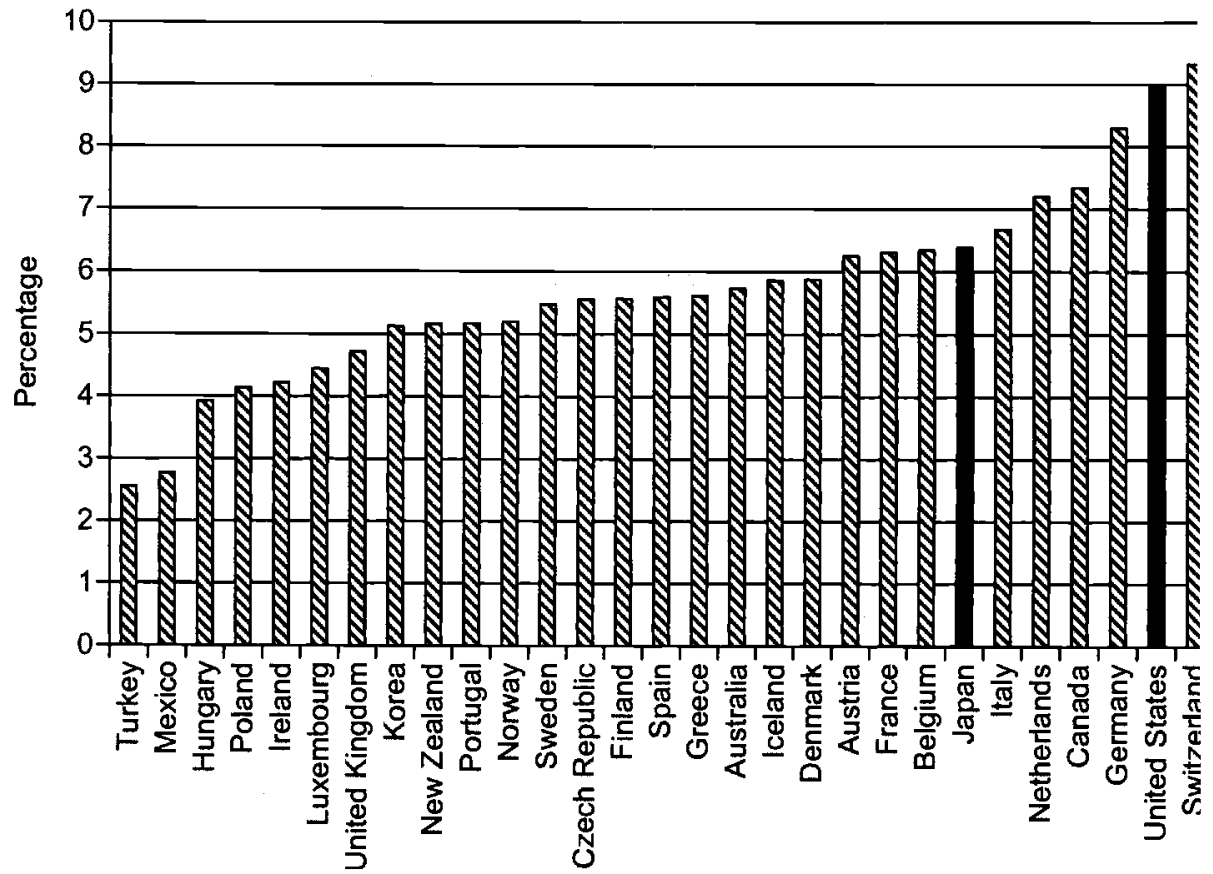

Fig. 3.5 Forecast change in medical care share of GDP, demographic and health cost changes, 2000-2030

Source: Author's calculations.

\subsection{Is Such Spending Sustainable?}

The increase in medical spending will have several implications for the economy. The first issue is whether such cost increases are good or harmful. Would society be harmed by spending so much on medical care?

Clearly, people can have different views about this. My belief is that increases in spending of this magnitude are affordable. Recall that economic growth is forecast to be relatively robust over the next half century. Hence, the size of the economic pie is expanding. The increase in medical care relative to GDP implies that the medical care slice of the pie is getting bigger. But the medical slice is not growing more rapidly than the pie itself. Even in these simulations, nonmedical consumption is still increasing over time.

Figure 3.6 shows this result analytically. I simulate nonmedical consumption assuming GDP increases by 2 percent annually and the differential between medical and nonmedical consumption is either 0 percent, 1 percent, or 2 percent annually. In ease case, nonmedical consumption rises from 2000 through 2050 . The increase is significantly larger in the case of no excess medical care cost growth (nearly 70 percent larger), but consumption increases in all scenarios. Inherently, continued medical care 


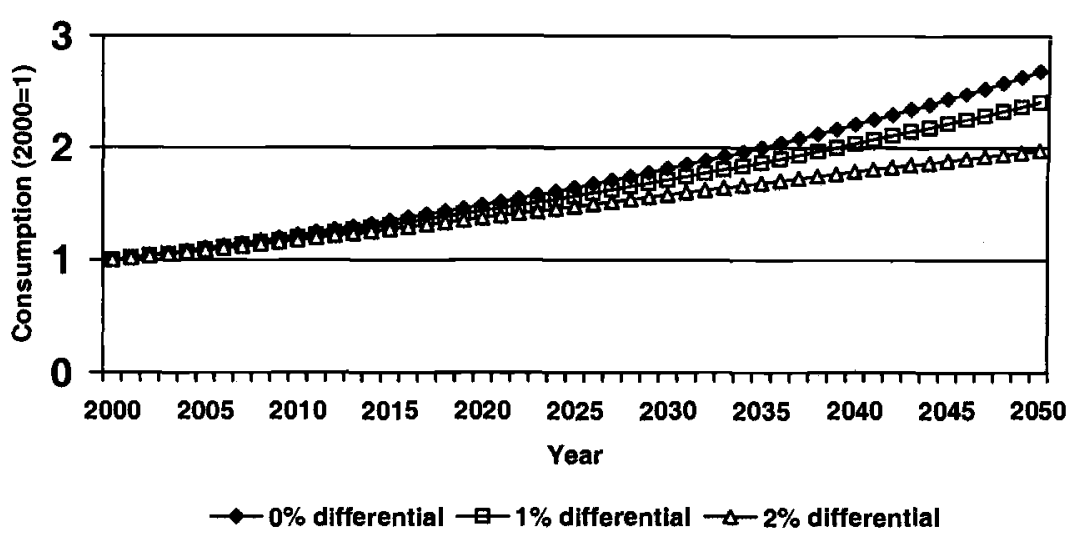

Fig. 3.6 Effect of increased medical costs on nonmedical consumption Source: Author's calculations.

cost growth involves is less rapid increase in nonmedical consumption, but not an absolute decline. That does not seem implausible.

The statement that we can afford to spend more on medical care does not mean that we should do so. Most Americans could afford a large screen TV, but not everyone chooses to do so. Other goods and services are important as well. We thus need to evaluate whether money spent on medical care is worth the expense.

This question cannot be answered using the simulations here. These simulations show what we will pay for medical advance, but not what we will get for it. To examine what we will get in return, we need to value the health improvements that result from medicine.

I have done this in other work (Cutler 2003). My conclusion is that medical spending is almost certainly worth the cost. We spend more on medical care, but we get even more in return. As an example, consider treatment changes in cardiovascular disease. As noted previously, the average forty-five-year-old is expected to live another five years now compared to 1950. Other work that I have done suggests that about three years of this improvement comes from medical advance in the treatment of coronary heart disease. These advances are of several forms: intensive medical care that saves the lives of people having a heart attack or other acute incident (bypass surgery, angioplasty, thrombolytic drugs, beta-blockers, cardiac catheterization, and so on) and medications taken on a regular basis that prevent the incidence of acute events or lessen their long-term consequences (antihypertensive medications, cholesterol lowering drugs, and the like). Together with public health improvements such as reduced smoking and lower fat diets, these changes have led to significant increases in longevity.

Those three years of life came at a cost, however. I estimate that the av- 
erage forty-five-year-old today will spend $\$ 30,000$ more on cardiovascular disease over his remaining life than the equivalent person would have in 1950.

Hence, the tradeoff: $\$ 30,000$ of spending for a three additional years of life. Is it worth it? Almost any sensible value for a year of life suggests that this is a good investment. A common metric in economics is that a year of life is worth about $\$ 100,000$. In present value, therefore, the three years of additional life from medical advances in the treatment of cardiovascular disease is worth about $\$ 120,000$ per person. This is four times the additional cost. The implication of this calculation is that medical spending is not bad. It is burdensome, to be sure, but not harmful overall.

\subsection{Summary and Implications}

The central issue in medical care is not whether we can afford to spend more on medicine or whether it is a good idea to do so, but how we should pay for it. There are three possible ways to pay for the coming medical care burden. The optimal tradeoff between them likely differs from country to country. To illustrate the issues involved, I focus on the possibilities in the United States.

The first option is to increase revenues from people currently alive to pay for medical care in the future. Money put aside now and saved until later can significantly reduce the burden of spending down the road. The increase in funds today can be either additional taxes, or (forced) private savings; economically, they are the same.

The preceding simulations give some guide as to what tax increase is necessary. If the government were to pay for all of the forecast increase, government spending in the United States would rise by about 9 percent of GDP in the coming three decades. If enacted immediately, a tax increase of a few percent of GDP would be needed to cover the deficit. Such a tax increase is large but not unheard of.

A second method is to wait until the future and then tax working generations to pay for the increased medical care burden that future elderly will incur. The simulations again show the size of the tax increase ultimately needed - 9 percent of GDP. That is a hefty amount. The efficiency consequences of such a tax would be a major issue.

The third solution is to make people pay more for medical care when they use services, especially at older ages. Many elderly in the United States face no cost sharing when using services. While Medicare requires such costs, a large number of the elderly purchase supplemental insurance or have such insurance from a former employer to offset the required cost sharing (Cutler and Wise, chap. 2 in this volume). As a result, care at the time of use is generally costless, and like all free services is overused. Making people pay more at the time of use is a viable option, although one 
would need to account for the welfare loss from increased risk bearing along with the gains from reduced moral hazard. A system with appropriate cost sharing would cost less than the current one.

Evaluating these different options is beyond the scope of this paper. With the near certainty of increases in medical costs in the next few decades, however, governments will increasingly have to face the issue of paying for an older population that uses increasingly intensive, and expensive, medical services.

\section{References}

Cutler, David M. 2003. Your money or your life. New York: Oxford University Press.

Cutler, David M., and Robert Huckman. 2003. Technological development and medical productivity: The diffusion of angioplasty in New York State. Journal of Health Economics 22 (2): 187-217.

Cutler, David M., and Ellen Meara. 1998. The medical costs of the young and old: A forty-year perspective. In Frontiers in the economics of aging, ed. David Wise, 215 42. Chicago: University of Chicago Press.

2001. The concentration of medical spending: An update. In Themes in the economics of aging, ed. David Wise, 217-34. Chicago: University of Chicago Press.

Cutler, David M., James Poterba, Louise Sheiner, and Lawrence Summers. 1990. An aging society: Opportunity or challenge? Brookings Papers on Economic Activity, Issue no. 1:1-56. Washington, DC: Brookings Institution.

Journal of the American Medical Association (JAMA). 2001. Thematic issue on "Forecasting Opportunities in Medical Research." 285 (5): 499-686.

Newhouse, Joseph. 1992. Medical care costs: How much welfare loss? Journal of Economic Perspectives 6 (3): 13-29.

Organization for Economic Cooperation and Development (OECD). OECD health data, 2002. Paris: OECD.

Technical Review Panel on the Medicare Trustees' Reports. 2000. Review of assumptions and methods of the Medicare trustees' financial projections. Washington, DC: Center for Medicare and Medicaid Services.

United Nations Population Division. 1998. World population prospects. New York: United Nations. 
This Page Intentionally Left Blank 